\title{
Necessity of facial contouring in feminization surgery for Chinese transgender females
}

\author{
Dong Li", Liang Xu", Zheyuan Yu, Jie Yuan, Min Wei \\ Department of Reconstructive and Plastic Surgery, Shanghai 9th People's Hospital, Shanghai Jiaotong University, Shanghai, China \\ Contributions: (I) Conception and design: M Wei, J Yuan; (II) Administrative support: Z Yu, L Xu, D Li; (III) Provision of study materials or patients: \\ M Wei, J Yuan, L Xu; (IV) Collection and assembly of data: D Li; (V) Data analysis and interpretation: D Li; (VI) Manuscript writing: All authors; (VII) \\ Final approval of manuscript: All authors. \\ "These authors contributed equally to this work. \\ Correspondence to: Min Wei, MD, PhD; Jie Yuan, MD, PhD. Department of Reconstructive and Plastic Surgery, Shanghai 9th People's Hospital, \\ Shanghai Jiaotong University, Shanghai 200023, China. Email: drwm1010@126.com; jaman1@126.com.
}

\begin{abstract}
Background: An increasing number of transgender females are suffering from a critical gender dysphoria, which often presents as depression and self-destructive behavior. Facial feminization surgery (FFS) is an effective method to alleviate symptoms of gender dysphoria, which could be more important than genital reassignment surgery for Chinese. Facial contour surgery is perceived as an ordinary FFS for the Chinese women to improve their facial appearance. The zygoma and jaw are key areas for feminizing the facial contour. This study mainly emphasized the necessity of FFS and discussed the importance of facial contour surgery of Chinese individuals.
\end{abstract}

Methods: The differences of facial contour before and after FFS in terms of skeletal and soft tissue were analyzed. The pre- and postoperative images were evaluated for feminization. The results of the full suite of measurements were compared to reveal the effective change of FFS. Furthermore, a surgery satisfaction survey was conducted among these patients after recovery.

Results: All the patients expressed their satisfaction with the reduction in the intergonial width as well as the middle face prominence. All the facial contour ratios changed significantly after surgery in both hard tissue and soft tissue.

Conclusions: Facial contour surgery is crucial to changing one's facial appearance and sex impression, which significantly alleviates gender dysphoria.

Keywords: Facial feminization surgery (FFS); Chinese transgender female; facial contour

Submitted Aug 14, 2020. Accepted for publication Jan 26, 2021.

doi: $10.21037 /$ atm-20-5887

View this article at: http://dx.doi.org/10.21037/atm-20-5887

\section{Introduction}

Gender dysphoria, known as gender disorder, develops due to the unconformity between one's assigned sex at birth and one's inherent gender identity (1). This incongruity between the biological gender and the appearance of the face may be severely distressing, and a large number of such patients yearn for the physical transition to alleviate this dysphoria for the perception of their sexual parts, which is "bad or unsatisfactory" or "very bad or very unsatisfactory."
Typically, patients with gender dysphoria are at a high risk of suffering from mental disorders (2).

A recent study revealed that the prevalence of transgender persons is estimated as 1 in 250 or approximately 1 million individuals in the United States (3). This population is unconsciously ignored with an ever-increasing number of individuals pursuing transgender surgery in China. About 400,000 transsexuals were estimated until 2002, which increased gradually in China. Globally, the number of 
transgender individuals exceeds 25 million, and the trend of gender-affirming surgery is continually rising (4).

Constrained by the traditional theories and perspectives, many of those suffering from gender dysphoria are not able to obtain psychological treatment and care in a timely manner before the active gender transition age in China. Consequently, the majority of the gender dysphoria patients start hormonal treatment after the onset of puberty when the bony facial structures develop a typical masculine appearance, and the results are often unexpected in patients undergoing male-to-female gender transition. On the other hand, a female-to-male gender transition patient is less frequently disturbed by the facial contour characteristics. Although gender reassignment surgery (GRS) has been demonstrated to reduce the levels of dysphoria, anxiety, and depression (5), existing studies suggested that patients who undergo transsexual operation show a much greater risk of death, self-destruction, suicidal behavior, and mental illness than general population (6). One explanation could be the fear of societal stigmatization. Therefore, the influence of social recognition and acceptance should not be underestimated (7). Therefore, altering the outward sexual characteristics has the potential for relieving gender dysphoria and facilitating social adaption, transition, and recognition for the transsexual community.

The masculine body appearance can be camouflaged by clothing to feminize. However, the face is not as easily hidden or dressed as other parts of the body. In most cultures, the face is essential for interpersonal interactions. The core effect of the face as a social tool is dedicated to the identification of gender, age, and race at a quick glance (8). The overall appearance of the feminine face is distinct from its masculine counterpart (9). The differences in facial structures, including zygoma, mandibular, chin, and nose, are collectively known as facial contour characteristics that create distinct dimorphism in facial appearance. Accumulating evidence displayed specific importance of the facial contour structures as they closely relate to the perceived congruence between bodily appearance and gender identity $(10,11)$.

In order to erase significant stigma and discrimination, a large number of transgender individuals, especially male-to-female pursue a feminine facial appearance by facial feminization surgery (FFS) after GRS. FFS is a collective term to describe the procedures that aim to feminize the face by altering the masculine appearance to feminine facial features, commonly performed for maleto-female transsexual individuals (12). However, it can also be undertaken for women who recognize that they have masculine facial characteristics and prefer a feminine appearance. Thus, feminization surgery is prevalent in the Oriental region due to the distinct culture differentiation.

Chinese FFS mainly includes gonial angle shave, malarplasty, reduction genioplasty, and rhinoplasty. In this study, we focused on mandibular and zygoma, the main elements of facial contour. As reported previously (13), an attractive feminine face contour should be round and softappearing with a heart, oval, or inverted triangle shape with respect to the ratio of the width of the middle face to the lower face. Compared to the Western female, the Chinese perceive that a refined and small face is more attractive. Therefore, the facial contour feminization surgery is crucial for their psychology and social adaptation.

We present the following article in accordance with the MDAR checklist (available at http://dx.doi.org/10.21037/ atm-20-5887).

\section{Methods}

As Asian females traditionally have masculinized jaws as well as lateral prominent zygomas, they are more fascinated with FFS in addition to the male-to-female transsexuals in China. Sixteen transgender females aged from 21 to 33 were included in this study. CT scan were taken before surgery and half a year after surgery. The data were excluded if loss to follow-up. A total of 16 sets of pre- and post-surgery computed tomography (CT) images of transgender females, who have undergone FFS, were examined three times randomly and blinded by three different technicians in this study. The images were collected from the Department of Plastic and Reconstructive Surgery, Shanghai $9^{\text {th }}$ People's Hospital. The CT scan images were acquired using a Siemens CT machine (Munich, Germany).

The study was conducted in accordance with the Declaration of Helsinki (as revised in 2013). The ethics approvals were obtained from the Shanghai $9^{\text {th }}$ People's Hospital Ethics Committee (ID: SH9H-2020-T430-2). Individual consent for this retrospective analysis was waived.

Linear and angular cranial measurements were obtained using craniometric definitions. Three-dimensional (3D) CT images were analyzed using Mimics 18.0 software; measurements, such as bizygomatic diameter (ZYB), bigonial width (GOG), and chin width $(\mathrm{CW})$ were found to be closely related to FFS, based on the visibility of landmarks. The skeletal and soft tissue differences, in terms of the facial contour between male and female, are 
Table 1 Facial skeletal contour differences between male and female faces

\begin{tabular}{ll}
\hline Male face & Female face \\
\hline Square and angulated with masculine jaw and chin & Heart-shaped, softer, oval with curving angle \\
Flat cheeks & Prominent- further anterior cheeks \\
Wider mandible with prominent angle & Mandible obtuse gonial angle \\
Long, square, and angulated chin & Chins are narrower, shorter and more pointed \\
\hline
\end{tabular}

illustrated in Table 1.

The pre- and postoperative images were measured and evaluated for feminization with the assistance of five professional craniofacial surgeons. The results of the full suite of measurements were compared to reveal the effective change of FFS by assessing gender appearance. The preoperative facial contour surgery design, according to the 3D-CT images (Figure 1), aimed for a feminized facial contour appearance. A successful FFS alters the preoperative sex assessment from male to female. The significance of FFS for transgender women is based on their facial skeletal contour characteristics and social interactions. Furthermore, a surgery satisfaction survey was conducted among these patients after recovery.

\section{Statistical analysis}

One-way analysis of variance was used to analyze the data. The differences in the face ratio between pre- and postoperative were assessed using Student's $t$-test. $\mathrm{P}<0.05$ was considered statistically significant. The satisfaction survey was completed independently without any intervention.

\section{Results}

The schematic of FFS related to facial contour is visualized in Figure 1, and the differences in facial contour are indicated in Figure 2. The masculine face exhibits a wider $\mathrm{ZYB}$ and GOG than the feminine face.

In the current study, postoperative swelling was recovered within 3-4 weeks. Although one patient presented hematoma, no infection occurred. Also, no other postoperative complications, such as nerve injury, pseudarthrosis, gingival recession, lost pulp vitality, and bone nonunion were detected in these patients. Postoperative images showed excellent and favorable feminized face contour. All patients expressed satisfaction with the reduction in the intergonial width as well as the

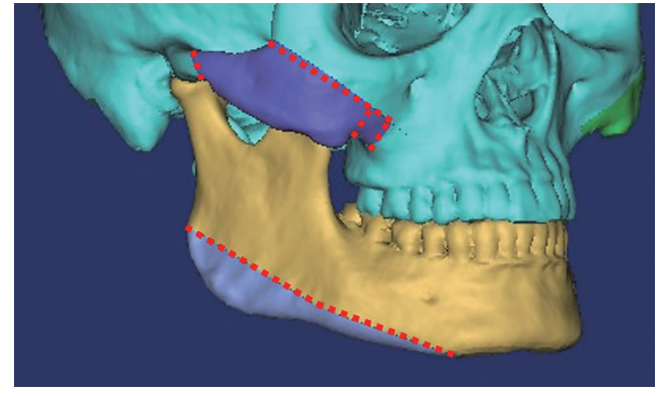

Figure 1 The schematic presurgery design of FFS related to facial contour in terms of malarplasty and mandibular shave surgery. FFS, facial feminization surgery.

middle face prominence. Typical cases and relevant 3D CT images are listed in Figures 3-6.

Similar to our previous report (14), the comparative data are shown in Tables 2 and 3, for the skeletal contour, the $\mathrm{ZYB} / \mathrm{GOG}$ changed from $1.13 \pm 0.06$ to $1.21 \pm 0.06$, the $\mathrm{ZYB} /$ FH changed from $1.10 \pm 0.07$ to $0.96 \pm 0.02$, and the GOF/ $\mathrm{FH}$ changed from $0.97 \pm 0.08$ to $0.79 \pm 0.04$. In soft tissue, the $\mathrm{ZYB} / \mathrm{GOG}$ changed from $1.08 \pm 0.05$ to $1.18 \pm 0.04$, the $\mathrm{ZYB} /$ FH changed from $1.21 \pm 0.06$ to $1.07 \pm 0.03$, and the GOF/ FH changed from $1.11 \pm 0.04$ to $0.92 \pm 0.05$. The ZYB, GOG, and the three ratios changed significantly after surgery in both hard and soft tissue. In addition, the sex assessment results altered after the facial contour surgery.

Most of the subjects were aware of the feminized facial contour (15/16 subjects, $93.75 \%$ ), and only one case showed concern about the swelling. When asked whether they care about the surgical trauma caused by FFS, the rate of "YES" was $62.5 \%$ (10 patients) vs. $12.5 \%$ (4 patients) of "NO", while the remaining subjects provided an undefined answer. However, all the patients declared that they would not worry about the trauma of surgery until the results of the surgery were satisfactory. Furthermore, only one case had hematoma, and 14/16 (87.5\%) patients were concerned about the complications, which might be due to their sufficient preoperative homework. Strikingly, none of them 

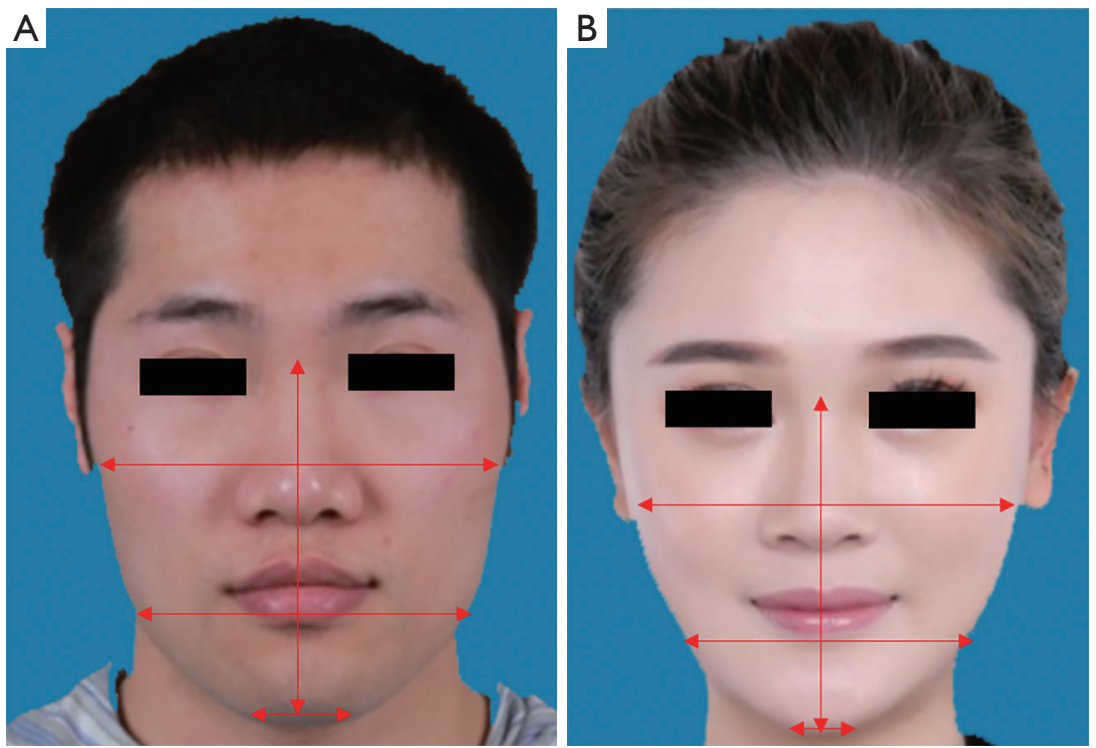

Figure 2 The typical Chinese masculine and feminized facial contour. (A) Typical Chinese male facial contour appearance. (B) Typical Chinese female facial contour appearance.
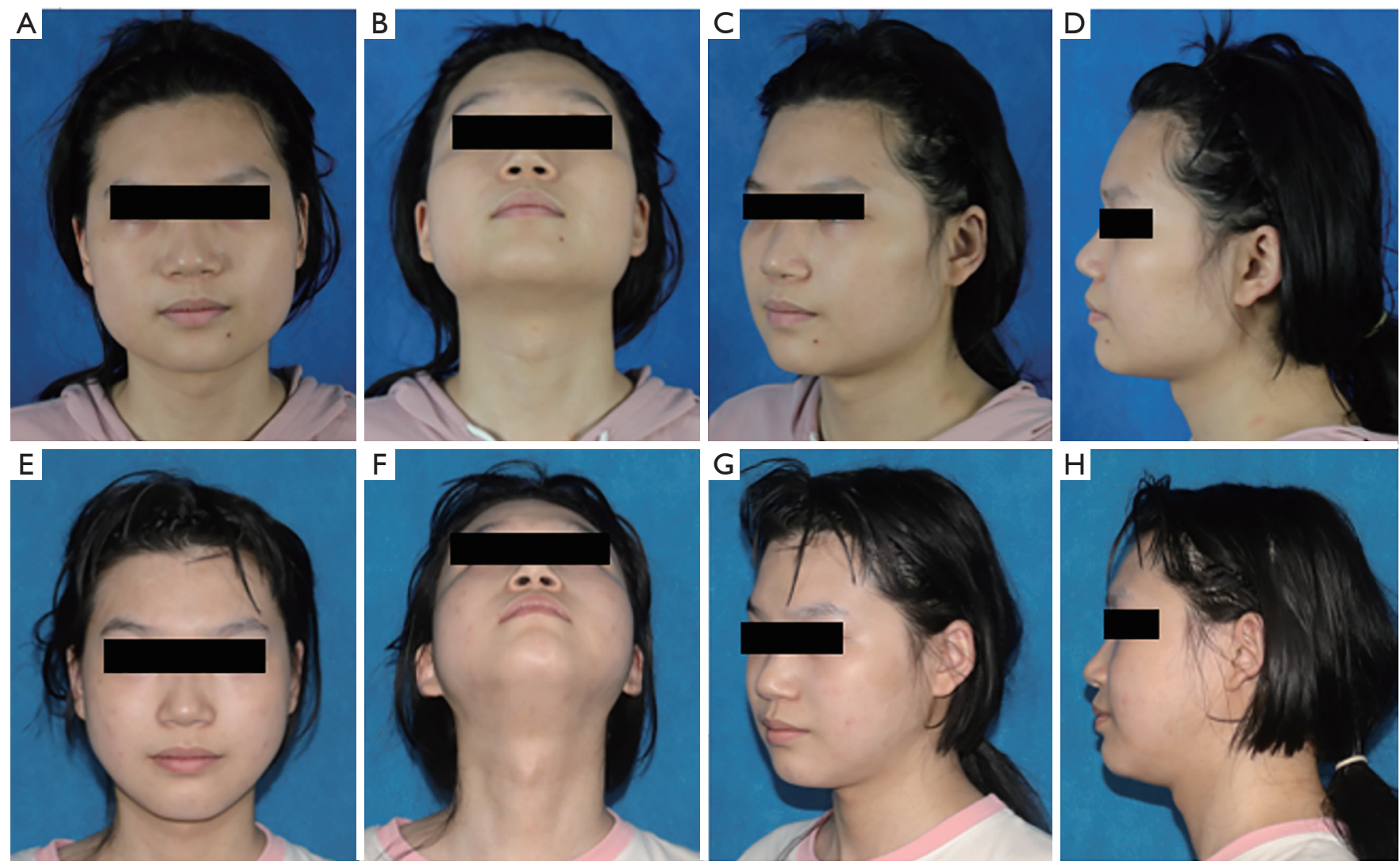

Figure 3 Typical feminized facial contour surgery of a transgender case who is on hormone replacement therapy, and malarplasty, gonial angle shave surgeries were performed. (A,B,C,D) Pre-surgery images of the patient. (E,F,G,H) Corresponding images of the same patient 3 months after facial contour surgery. 

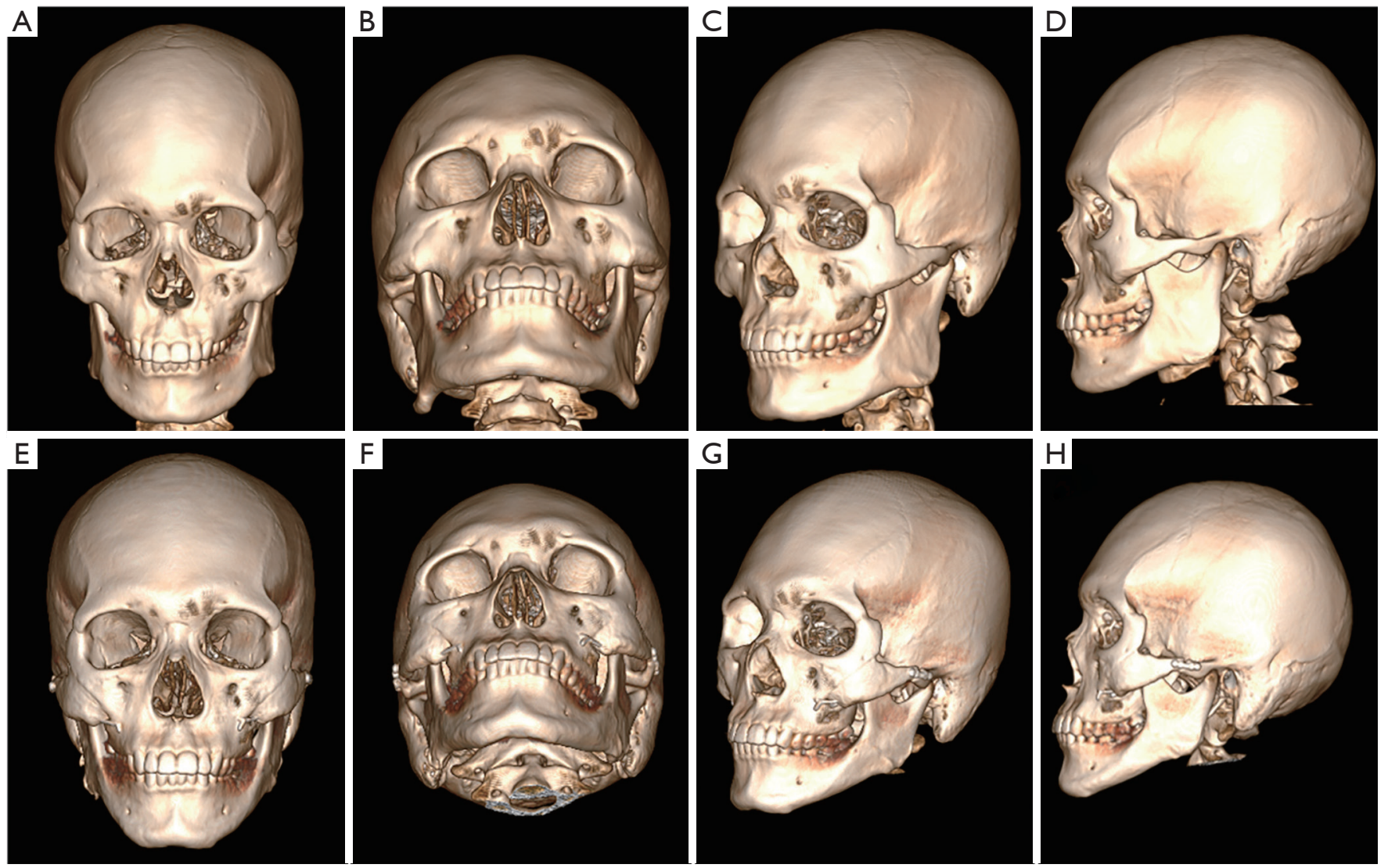

Figure 4 3D CT images of the same case in Figure 3. (A,B,C,D) Pre-surgery 3D CT images of the patient. (E,F,G,H) Corresponding 3D CT images of the same patient 3 months after facial contour surgery.

complained about the postoperative care. The patients, their relatives, and their friends reported that FFS improved the facial contour as well as mental stress.

\section{Discussion}

Recent reports confirmed the tangible benefits of FFS for the quality of life and the improved psychosocial fitness of gender dysphoria patients (15). This was consistent with the current results that the FFS facilized the transgender individuals to obtain an attractive feminine facial appearance and help them to quickly and effectively reintegrate into the society. However, the FFS needs to be assessed cautiously for a satisfactory result.

Nonetheless, all the patients should be subjected to a preoperative evaluation by cephalometrics analysis, which is used to assess the possible facial contour ratio. However, there are no clear guidelines for patients who underwent FFS (1). Thus, consulting a mental health provider before
FFS in case of an unexpected dispute is recommended. Similarly, hormone therapy prior to surgery is preferred for remodeling and texturizing of the soft tissues to fit their true gender. Also, a complete evaluation by a dentist and orthodontist is essential before undertaking mandibular angle shave recontouring. Previous photographs, plain radiographs, or CT imaging are employed to assess the entire face to determine the feminine and masculine aspects. The other associated risks, such as infection, bleeding, and uncontrolled diabetes, should be disclosed and processed before performing FFS. The putative sequelae of facial contour surgery, such as asymmetry, nerve injury, dermatolysis, scar, second mandibular angle, and bone union, can be prevented in advance by an adequate preoperative surgical design and a carefully invasive intraoperative operation. When the sequelae occurred, the evaluation and analysis should be performed immediately in order to identify the possible cause. Subsequently, the treatment measures should be scheduled according to the 

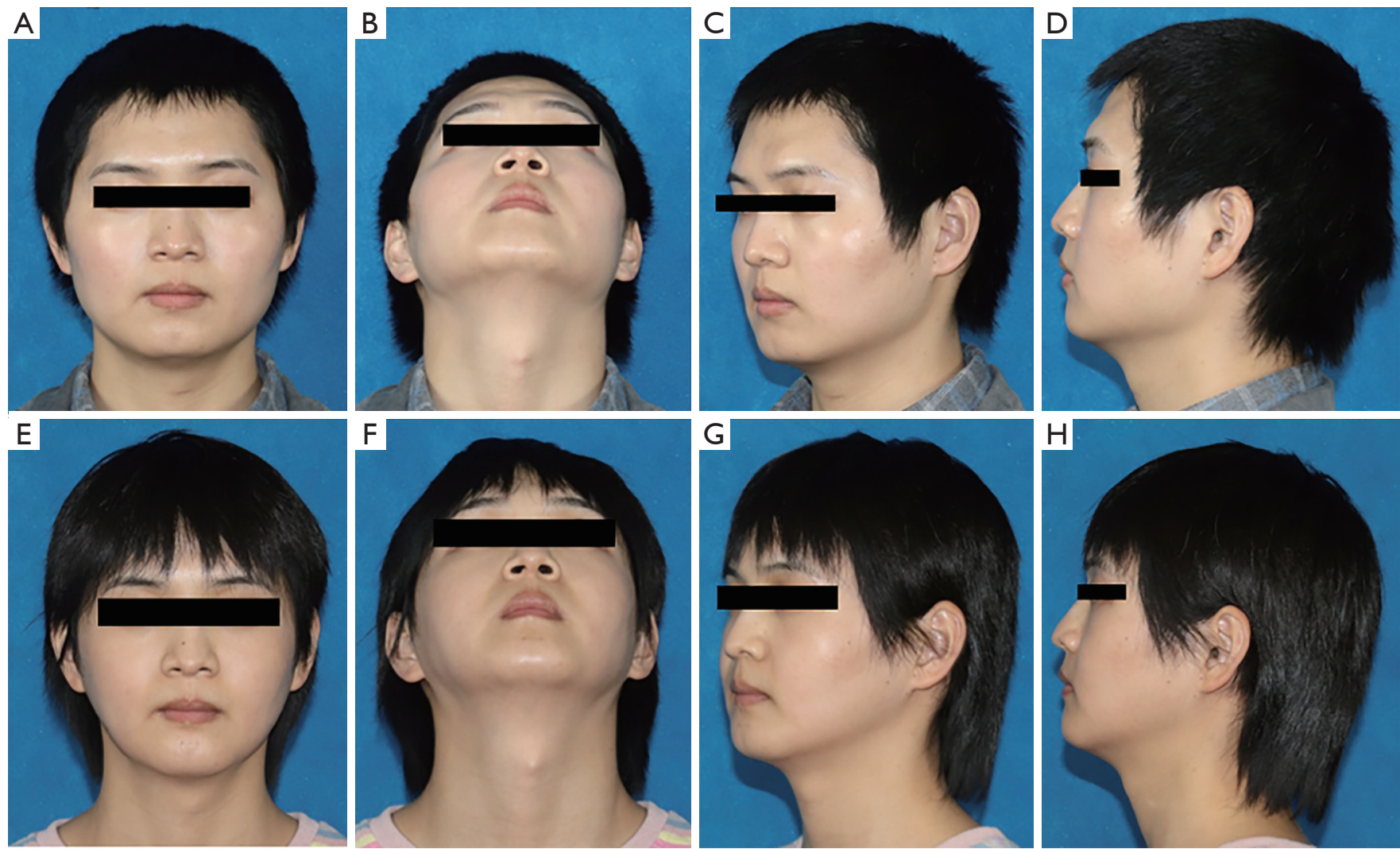

Figure 5 Typical feminized facial contour surgery case, malarplasty, gonial angle shave surgeries and genioplasty were performed. (A,B,C,D) Pre-surgery images of the patient. (E,F,G,H) Corresponding images of the same patient 3 days after facial contour surgery.

individuals. For example, once nerve injury is detected, the degree of nerve damage is evaluated first, followed by nerve repair procedure and mecobalamin tablets. The key to successful surgical planning for these transgender patients is to obtain an in-depth insight into the individual anatomy towards fulfilling the patient's goals for transformation.

The majority of the existing studies for FFS focus on the modification of certain parts of the face $(2,4,16-20)$. The modification of the whole facial skeleton contour traits consists of mandibular angle osteotomy, genioplasty, and malarplasty reduction in Chinese transsexuals is rarely reported.

The skeleton contour of the lower face is the morphology of the mandible and the chin. Forensic scientists suggested that the mandibular segments can be used to accurately predict the biological sex assigned at birth (21). The masculinized mandible is characterized by a wide bigonial angle and prominence at the mandibular angle. However, this might not be appropriate for some of the Asian women who have masculinized jaws. The masculine chin is square and wide, with an increased vertical height. An osteoplastic genioplasty is used to vertically shorten or narrow the chin as displayed in Figures 4 and 5. The jaw and chin were crucial for the lower feminine face, especially in Asian females.

According to the current survey, almost half of the Chinese women manifested a wide bigonial angle as well as a prominent mandibular angle; among these, onethird exhibited a masculine chin. Thus, the jaw and chin feminization surgery can be performed either separately or together, depending on the individual's anatomy. Intriguingly, an increasing number of patients, including transgender females and the original females, are obsessed with mandibular angle osteotomy or genioplasty in China.

The middle-feminized face is round and open. While masculine midfaces are flatter than feminine midfaces, the zygoma is prominent laterally, whereas the feminized malar prominence is positioned anteriorly (22). Hairline, forehead, brows, lips, mandible, and chin were considered as ordinary FFS in previous studies, while malarplasty reduction, which 

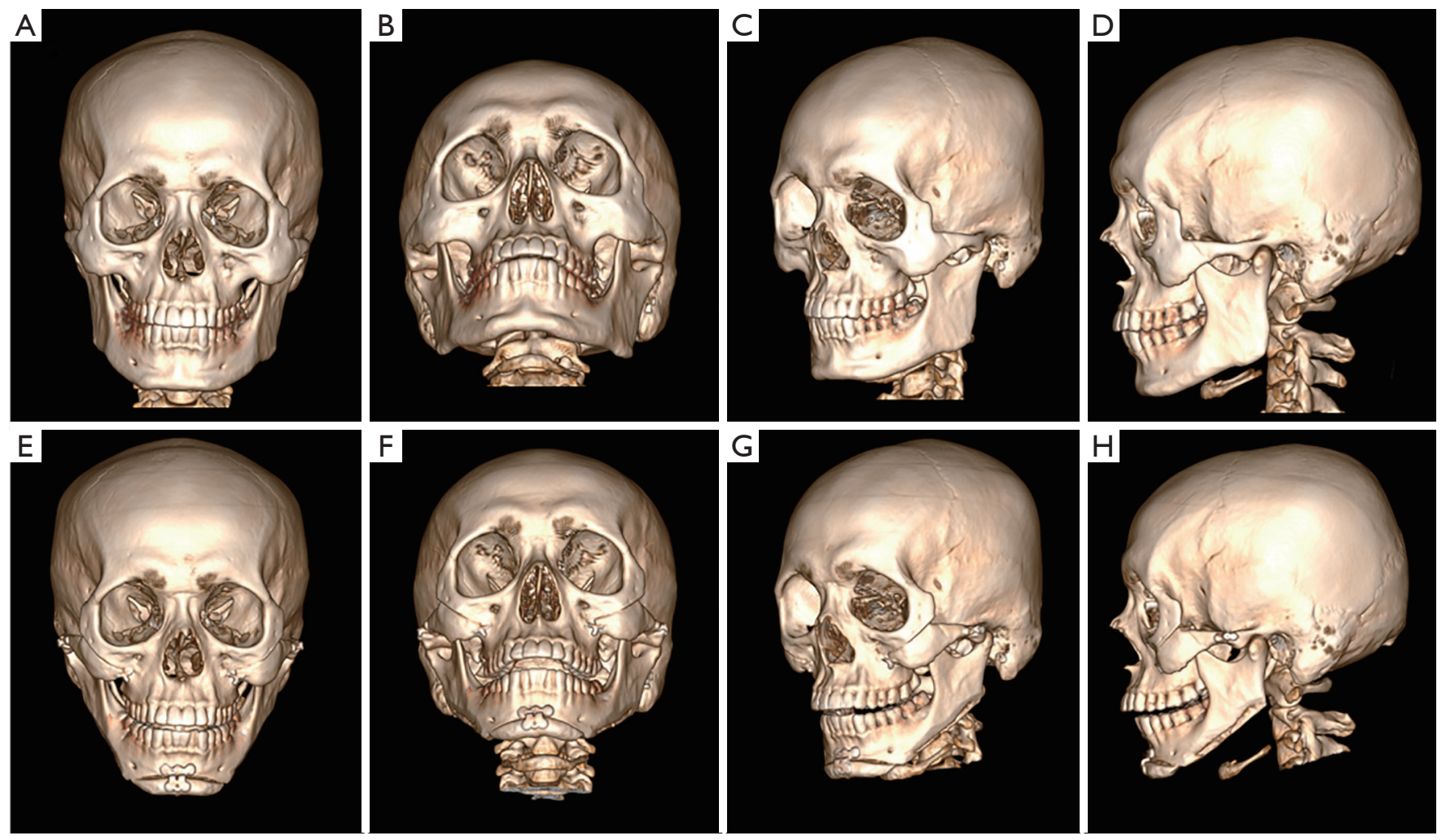

Figure 6 3D CT images of the same case in Figure 5. (A,B,C,D) Pre-surgery 3D CT images of the patient. (E,F,G,H) Corresponding 3D CT images of the same patient 3 days after facial contour surgery.

Table 2 Measurements of pre- and post-operation of skeletal facial contour

\begin{tabular}{lcr}
\hline Measurements & Pre operation & Post-operation \\
\hline Bi-zygomatic diameter (ZYB), mm & $128.37 \pm 5.99$ & $116.18 \pm 3.82$ \\
Bi-gonial width (GOG), mm & $113.69 \pm 6.73$ & $95.81 \pm 4.92$ \\
Face height (FH), mm & $116.51 \pm 5.17$ & $120.97 \pm 3.47$ \\
ZYB/GOG, mm & $1.13 \pm 0.06$ & $1.21 \pm 0.06$ \\
ZYB/FH, mm & $1.10 \pm 0.07$ & $0.96 \pm 0.02$ \\
GOG/FH, mm & $0.97 \pm 0.08$ & $0.79 \pm 0.04$ \\
\hline
\end{tabular}

might be the unique necessity for Chinese transsexual females, should also be taken into account. Unlike other races whose malar prominence may need to be augmented in order to obtain the typically described inverted triangle of the feminized mid and lower face, the Chinese attractive female face, relatively small, delicate, and round, which is the result of malarplasty reduction and mandibular angle shave surgery. We also found that the transgender females are more likely to be satisfied with facial skeleton contour surgery than the real Chinese women with a masculine appearance. The feminization of the mandible may involve osteotomy or burring of the lower border and/or angle of the mandible (23). Notably, the friction drill often results in hyperostosis along with discordant jawlines. To avoid this phenomenon, we preferred to use a reciprocal saw for the main part in the osteotomy.

In addition to facial bone contouring, soft tissue should also be considered. For optimal facial contouring, partial 
Table 3 Measurements of pre- and post-operation of soft tissue of facial contour

\begin{tabular}{lcc}
\hline Measurements & Pre operation & Post-operation \\
\hline Bi-zygomatic diameter (ZYB), mm & $149.57 \pm 10.48$ & $139.84 \pm 7.92$ \\
Bi-gonial width (GOG), mm & $137.75 \pm 12.15$ & $120.81 \pm 8.64$ \\
Face height (FH), mm & $123.12 \pm 7.34$ & $130.05 \pm 5.38$ \\
ZYB/GOG, mm & $1.08 \pm 0.05$ & $1.18 \pm 0.04$ \\
ZYB/FH, mm & $1.21 \pm 0.06$ & $1.07 \pm 0.03$ \\
GOG/FH, mm & $1.11 \pm 0.04$ & $0.92 \pm 0.05$ \\
\hline
\end{tabular}

masseter resection is performed for patients with masseter hypertrophy. In addition, facial fat suction is adopted for a clear mandibular contour to cure the fat accumulation in the middle and lower part of the face.

A proper facial contour surgery should include the following procedures: preoperative interview and communication, preoperative design and communication, preoperative preparation, anesthesia, operation, postoperative recovery, and follow-up. In order to complete a facial contour surgery, carefully preoperative communication is required to understand the effects on the patients. Meanwhile, the preoperative measurement is important to guarantee a successful facial contour surgery. Following preoperative preparation, the preoperative designed facial contour surgeries could be completed smoothly and precisely within several hours.

Maintaining the preoperative design in a relatively small operating space is the main technical difficulty for every surgeon. This can be alleviated as follows: (I) accurate individualized preoperative design; (II) appropriate muscle relaxants application; (III) sufficient soft tissue dissection and protection is needed; (IV) avoid excessive retractor pulling; (V) intraoperative navigation confirmation is suggested.

Furthermore, patients with gender dysphoria prefer feminizing makeup and hair to cover their masculine face shape. Botox masseter injection can be used for transexuals with less bony masculinization to obtain a feminized face. Psychological counseling is an alternative way to intervene gender dysphoria. However, according to the current experience, most of the above methods can only relieve part of their disorder. Facial contour surgery seems to be a suitable way to alleviate the disorder maximally.

Although there are a series of surgical and non-surgical interventions for facial feminization, this study highlights the importance of facial skeleton feminization surgery. We proposed that facial skeleton contour surgery is beneficial before the ordinary soft tissue FFS to obtain a harmonious facial appearance.

Subsequently, other observation indicators and inspection results, such as the thickness of soft tissue after facial contour surgery, the effect of bone absorption to facial droops, and long-term satisfaction of the surgery need to be considered. However, the number of transsexual patients in China remains relatively small, necessitating the accumulation of relevant cases and addition of observation indicators and inspection results to substantiate the current findings.

\section{Conclusions}

The results of this study demonstrated that facial skeletons exhibit masculine specificities that can be altered by FFS by a Plastic or Craniofacial Surgeon. The postoperative FFS patients appear female morphologically with respect to the facial traits and are satisfied with their feminine face. Thus, it is imperative that FFS should be considered as the necessary gender-confirming surgery besides transsexual surgery for Chinese women.

Subsequently, the psychological barrier of transsexual patients may be partially eliminated due to the altered sex in physical appearance. Thus, it is our responsibility to be aware of the dysphoria of nonconforming gendered individuals, which can be alleviated by changing their facial appearances, especially the male-to-female facial traits. Nonetheless, further studies are required to understand the long-term effect of FFS in gender dysphoria patients with respect to the quality of their social life.

\section{Acknowledgments}

We acknowledge the contribution of Qi Fan, Yehong 
Zhong, and Yijia Zhu. We would like to thank Sunil Saroj for his help in polishing the language of our paper.

Funding: This study was supported by the Biobank Project of Shanghai ${ }^{\text {th }}$ People's Hospital (Grant No. YBKB201909).

\section{Footnote}

Provenance and Peer Review: This article was commissioned by the Guest Editors (Drs. Oscar J. Manrique, John A Persing, and Xiaona Lu) for the series "Transgender Surgery" published in Annals of Translational Medicine. The article has undergone external peer review.

Reporting Checklist: The authors have completed the MDAR checklist. Available at http://dx.doi.org/10.21037/atm-205887

Data Sharing Statement: Available at http://dx.doi. org/10.21037/atm-20-5887

Conflicts of Interest: All authors have completed the ICMJE uniform disclosure form (available at http://dx.doi. org/10.21037/atm-20-5887). The series "Transgender Surgery" was commissioned by the editorial office without any funding or sponsorship. The authors have no other conflicts of interest to declare.

Ethical Statement: The authors are accountable for all aspects of the work in ensuring that questions related to the accuracy or integrity of any part of the work are appropriately investigated and resolved. The study was conducted in accordance with the Declaration of Helsinki (as revised in 2013). The ethics approvals(ID:SH9H2020-T430-2) were obtained from the Shanghai $9^{\text {th }}$ People's Hospital Ethics Committee. Individual consent for this retrospective analysis was waived.

Open Access Statement: This is an Open Access article distributed in accordance with the Creative Commons Attribution-NonCommercial-NoDerivs 4.0 International License (CC BY-NC-ND 4.0), which permits the noncommercial replication and distribution of the article with the strict proviso that no changes or edits are made and the original work is properly cited (including links to both the formal publication through the relevant DOI and the license). See: https://creativecommons.org/licenses/by-nc-nd/4.0/.

\section{References}

1. Coleman E, Bockting W, Botzer M, et al. Standards of Care for the Health of Transsexual, Transgender, and Gender-Nonconforming People, Version 7. Int J Transgend 2012;13:165-232.

2. Lundgren KC, Koudstaal MJ. Midfacial Bony Remodeling. Facial Plast Surg Clin North Am 2019;27:221-6.

3. Meerwijk EL, Sevelius JM. Transgender Population Size in the United States: a Meta-Regression of Population-Based Probability Samples. Am J Public Health 2017;107:e1-8.

4. Morrison SD, Satterwhite T. Lower Jaw Recontouring in Facial Gender-Affirming Surgery. Facial Plast Surg Clin North Am 2019;27:233-42.

5. Facque AR, Atencio D, Schechter LS. Anatomical Basis and Surgical Techniques Employed in Facial Feminization and Masculinization. J Craniofac Surg 2019;30:1406-8.

6. Suicide Attempts Among Transgender and Gender NonConforming Adults: Findings of the National Transgender Discrimination Survey. New York, NY; Los Angeles, CA: American Foundation for Suicide Prevention and The Williams Institute, 2014. Accessed March 29, 2018. Available online: https://williamsinstitute.law.ucla.edu/ research/suicide-attempts-among-transgender-andgender-non-conforming-adults/

7. Plemons E. Formations of Femininity: Science and Aesthetics in Facial Feminization Surgery. Med Anthropol 2017;36:629-41.

8. Sykes JM, Dilger AE, Sinclair A. Surgical Facial Esthetics for Gender Affirmation. Dermatol Clin 2020;38:261-8.

9. Morrison SD, Vyas KS, Motakef S, et al. Facial Feminization. Plast Reconstr Surg 2016;137:1759-70.

10. Dhejne C, Lichtenstein P, Boman M, et al. Longterm follow-up of transsexual persons undergoing sex reassignment surgery: cohort study in Sweden. Plos One 2011;6:e16885.

11. Isung J, Möllermark C, Farnebo F, et al. Craniofacial Reconstructive Surgery Improves Appearance Congruence in Male-to-Female Transsexual Patients. Arch Sex Behav 2017;46:1573-6.

12. Parker K, Naini FB, Gill DS, et al. Facial feminisation: an overview of the role of the surgeon and orthodontist. J Orthod 2019;46:148-54.

13. Li D, Mao H, Yu Z, et al. Primary aesthetic correction of nasal anomaly with costal graft in treating orbital hypertelorism. J Craniomaxillofac Surg 2018;46:6-10.

14. Li D, Xu H, Xu L, et al. The Aesthetic Proportion Index of Facial Contour Surgery. J Craniofac Surg 2015;26:586-9. 


\section{Page 10 of 10}

15. Spiegel JH. Challenges in care of the transgender patient seeking facial feminization surgery. Facial Plast Surg Clin North Am 2008;16:233-8.

16. Spiegel JH. Considerations in Feminization Rhinoplasty. Facial Plast Surg 2020;36:53-6.

17. Schall JL, Rogers TL, Deschamps-Braly JC. Breaking the binary: The identification of trans-women in forensic anthropology. Forensic Sci Int 2020;309:110220.

18. Eggerstedt M, Hong YS, Wakefield CJ, et al. Setbacks in Forehead Feminization Cranioplasty: A Systematic Review of Complications and Patient-Reported Outcomes. Aesthetic Plast Surg 2020;44:743-9.

19. Gilde JE, Shih CW, Kleinberger AJ. Frontal Sinus

Cite this article as: $\mathrm{Li} \mathrm{D}, \mathrm{Xu} \mathrm{L}, \mathrm{Yu} \mathrm{Z}$, Yuan J, Wei M. Necessity of facial contouring in feminization surgery for Chinese transgender females. Ann Transl Med 2021;9(7):603. doi: $10.21037 /$ atm-20-5887

\section{Li et al. Necessity of facial contouring in feminization surgery}

Transillumination in Cranioplasty for Facial Feminization Surgery. JAMA Facial Plast Surg 2019;21:566-7.

20. Mommaerts MY, Voisin C, Joshi Otero J, et al. Mandibular feminization osteotomy-preliminary results. Int J Oral Maxillofac Surg 2019;48:597-600.

21. Tunis TS, Sarig R, Cohen H, et al. Sex estimation using computed tomography of the mandible. Int J Legal Med 2017;131:1691-700.

22. Altman K. Facial feminization surgery: current state of the art. Int J Oral Maxillofac Surg 2012;41:885-94.

23. Morris DE, Moaveni Z, Lo L. Aesthetic Facial Skeletal Contouring in the Asian Patient. Clin Plast Surg 2007;34:547-56. 